\title{
Pearls \& Oy-sters: IV and mechanical thrombolysis for ischemic stroke secondary to cardiac myxoma
}

Tamara Barghouthi, MD, Ava Giugliano, DO, J.W. Lisa Kim-Shapiro, MD, and Quang Vu, MD

Neurology ${ }^{\circledR}$ 2019;93:975-977. doi:10.1212/WNL.0000000000008549

\section{Correspondence}

Dr. Barghouthi

tbarghou@wakehealth.edu

\section{Pearls}

- Cardiac myxoma is a rare cause of both ischemic and hemorrhagic strokes.

- Thrombolytic and endovascular treatment of acute ischemic stroke secondary to cardiac myxoma can be safe and effective.

\section{Oy-sters}

- Cardiac myxoma should be included in the differential diagnoses for acute ischemic stroke, particularly if the embolus has an abnormal appearance.

- Cardiac myxomas discovered as the source of a stroke should be surgically removed as soon as it is safe to do so given the risk of recurrent embolism.

A 49-year-old man with no relevant medical history presented to the emergency department with sudden-onset right-sided weakness and aphasia. Initial NIH Stroke Scale score was 20 for global aphasia, dysarthria, right hemibody plegia, right-sided neglect, and left gaze preference. Initial head CT showed a hypodensity throughout the left basal ganglia and left hemispheric deep white matter concerning for acute ischemia (figure, A). CT angiography of the head and neck demonstrated complete filling defects involving the left carotid terminus and proximal middle cerebral artery (MCA)/anterior cerebral artery (ACA) segments with distal MCA and ACA vessel reconstitution via collateral flow (figure, B). CT perfusion showed significant ischemic penumbra surrounding the infarction. The patient was deemed a candidate for IV tissue plasminogen activator (tPA) and infusion was started 1 hour and 41 minutes after time of last known normal. He was then emergently taken to interventional radiology for angiography and mechanical thrombectomy. Angiography confirmed complete occlusion of the left MCA M1 segment (figure, C). Mechanical thrombectomy was performed using aspiration and 3 passes were required to achieve reperfusion, resulting in a thrombolysis in cerebral infarction (TICI) score of 3 (figure, D). A large, gelatinous, white-appearing embolus was removed, which did not resemble typical arterial clots (figure, E). Due to its atypical appearance, the embolus was sent for pathologic assessment.

The patient's neurologic examination improved significantly following thrombectomy. Brain MRI was unable to be performed due to the patient having BB fragments in his neck. Head CT without contrast performed the following day showed an evolving infarct involving the left basal ganglia and adjacent white matter with hyperattenuation of the left putamen, likely a combination of contrast staining and petechial hemorrhage (figure, F). Transthoracic echocardiogram revealed a large, $7.7 \times 3.0 \mathrm{~cm}$, mobile mass within the left atrium, protruding into the left ventricle, attaching to the atrial septum and obstructing the mitral valve (figure, $G$ ). Contrast was seen in the mass and ejection fraction was $55 \%$. Cardiothoracic surgery was consulted and recommended resection of the left atrial mass when safe to anticoagulate for surgery from a neurologic perspective. Although the patient was at risk of hemorrhage in the setting of recent thrombectomy and evidence of petechial hemorrhage on imaging, it was believed the benefits

From the Departments of Neurology (T.B., A.G., Q.V.) and Pathology (J.W.L.K.-S.), Wake Forest Baptist Medical Center, Winston-Salem, NC.

Go to Neurology.org/N for full disclosures. Funding information and disclosures deemed relevant by the authors, if any, are provided at the end of the article. 

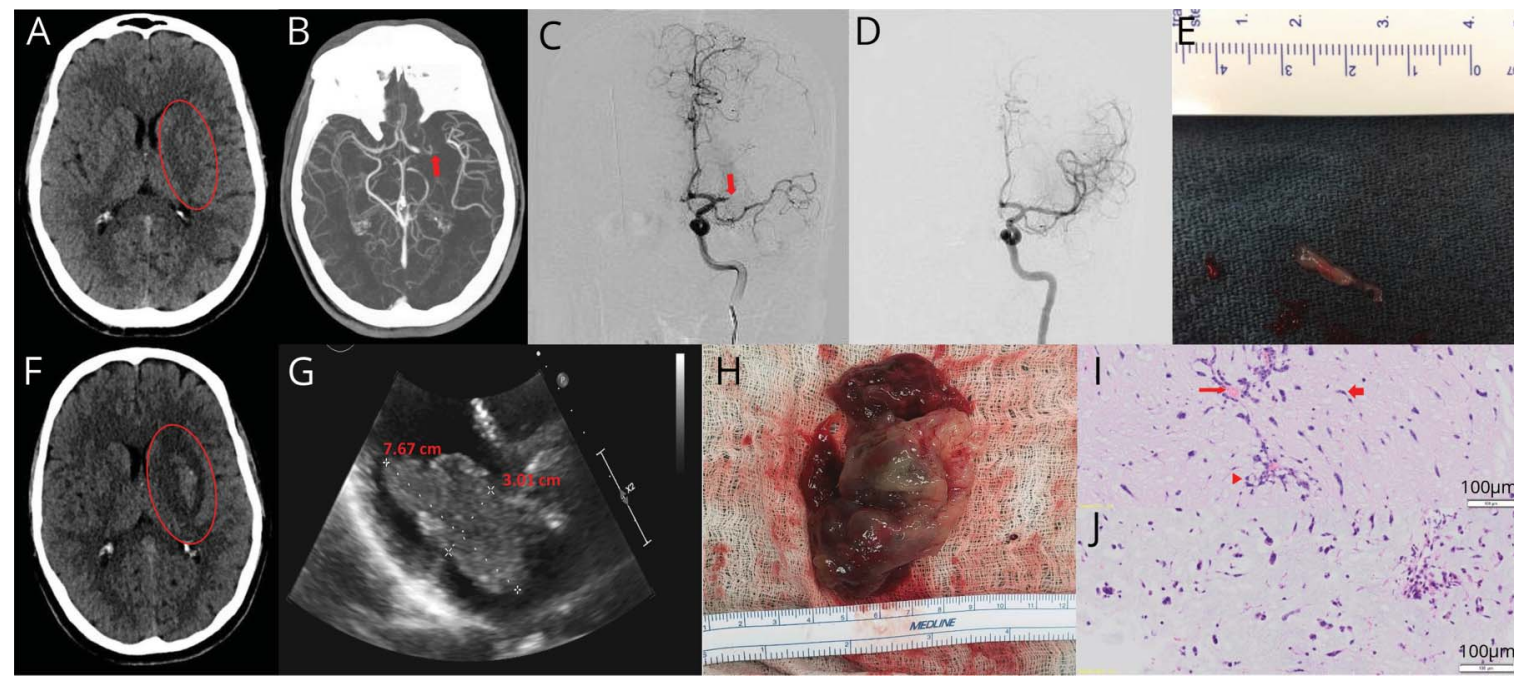

(A) Initial head CT shows left hemispheric hypodensities. (B) CT angiography of the head and neck shows filling defects of the left carotid terminus and proximal MCA/anterior cerebral artery with distal vessel reconstitution. (C) Angiography shows complete occlusion of the left middle cerebral artery M1 segment. (D) Mechanical thrombectomy resulting in thrombolysis in cerebral infarction 3 reperfusion. (E) Gross appearance of the removed cerebral embolus. (F) Head CT without contrast performed the following day shows evolving left hemispheric infarcts with hyperattenuation of the left putamen. (G) Transthoracic echocardiogram shows a $7.67 \times 3.01 \mathrm{~cm}$ atrial myxoma within the left atrium and ventricle. (H) Gross appearance of the resected atrial myxoma. (I) Microscopic appearance of the atrial myxoma (hematoxylin \& eosin stain, 40x magnification). Arrowhead: complex cluster; short arrow: spindle cell; long arrow: blood vessel. ()) Microscopic appearance of the embolic specimen consistent with low-grade myxoid neoplasm (hematoxylin \& eosin stain, 40× magnification).

would outweigh the risks of possible recurrent emboli and additional stroke. The patient was fully anticoagulated 1 week after thrombectomy and taken for removal of the left atrial mass.

Pathologic gross examination of the resected specimen revealed a $35 \mathrm{~g}, 6.7 \times 4.8 \times 3.0 \mathrm{~cm}$, red-brown left atrial mass, described as having hemorrhagic, gelatinous, and heterogeneous cut surfaces (figure, $\mathrm{H}$ ). Microscopic examination was consistent with a cardiac myxoma (figure, I). The embolic specimen retrieved during thrombectomy was found on pathologic assessment to be consistent with a low-grade myxoid neoplasm (figure, J). When comparing the myxoma to the cerebral embolus, the 2 specimens were histologically similar, thereby providing evidence that the left atrial myxoma was the origin of the cerebral embolus. While myxoma surface clots or clots formed secondary to atrial fibrillation can also lead to strokes, this was not the case in this patient, as evidenced by the gross and histologic analysis of the cerebral embolus.

On postoperative day 3 , the patient developed atrial fibrillation with rapid ventricular rate, which subsequently converted to sinus rhythm with the use of amiodarone. He was discharged on postoperative day 6 with aspirin $81 \mathrm{mg}$ daily and rosuvastatin $10 \mathrm{mg}$ daily for secondary stroke prevention and amiodarone for rhythm control. At his neurology clinic follow-up roughly 1 week after discharge, he had mild dysarthria, muscle strength of $4+/ 5$ in the right upper extremity and $5 / 5$ strength in the right lower extremity, and a modified Rankin Scale score of 2.

\section{Discussion}

Cardiac myxomas are a rare but important cause of cardioembolic stroke. Primary tumors of the heart are rare, with an incidence of $0.0017 \%-0.19 \%$ at autopsy, with atrial myxomas being the most common, comprising up to $80 \%$ of primary heart tumors. ${ }^{1,2}$ Cardiac myxomas occur most commonly in the third to sixth decades of life but can occur at any age and are more common in female patients in a $>2: 1$ ratio. ${ }^{1-4}$ Most cardiac myxomas $(75 \%)$ originate from the left atrium and less commonly are found in the right atrium, bilateral atria, heart valves, and only $3 \%-4 \%$ detected in either ventricle. There have also been reports of combined atrial and ventricular myxomas. ${ }^{1}$ Histologically, myxomas are composed of stellate, spindle, or polygonal cells in nests, cords, or complex structures, often surrounding vessels, within acid-mucopolysaccharide-rich stroma. ${ }^{1,4}$ Myxoma characteristics including mobility, size, location, and type are associated with likelihood of embolism. ${ }^{1-3}$ The consistency of the myxoma determines its mobility, with villous extensions being fragile with greater tendency to fragment and embolize. ${ }^{1,4}$ Systemic emboli occur in $30 \%-50 \%$ of patients with myxoma with over $50 \%$ of emboli going to the CNS and retinal arteries. ${ }^{2-4}$ Cardiac myxomas are the cause of $<1 \%$ of ischemic strokes. ${ }^{5,6}$ Hemorrhagic stroke is less common and is related to the formation of cerebral aneurysms. ${ }^{2}$ Aneurysm formation occurs when myxoma embolization leads to infiltration of a vessel wall by the embolus causing weakening of the vessel wall. ${ }^{2,7}$

Studies of stroke secondary to cardiac myxoma are largely limited to case reports and small series. A 2015 comprehensive 
literature collection of stroke of cardiac myxoma origin described the features of this rare condition from cases of 133 patients between 2000 and 2014. They found that stroke secondary to cardiac myxoma most commonly occurred in young adults, with a female predominance. The most common neurologic symptoms were hemiparesis (51 of 104 patients, 49\%), aphasia (29 of 104 patients, 27.9\%), and alteration of consciousness (24 of 104 patients, 23.1\%). Cardiac myxoma detection was most often made after the diagnosis of stroke. Cardiac myxomas were most commonly located in the left atrium (105 of 112 myxomas, 93.8\%). Delayed surgical resection was associated with increased risk of complications from the myxoma. ${ }^{5}$

A 2001 case series of 112 patients with left atrial cardiac myxomas showed that $29 \%$ of patients in the study had systemic emboli, with $72.7 \%$ of those ( 24 of 33 patients) having CNS emboli. The presence of a villous tumor surface was significantly associated with cerebral and peripheral embolism. ${ }^{4} \mathrm{~A}$ 2004 review of 113 patients with cardiac myxoma with neurologic presentation showed that ischemic stroke/TIA was the most common neurologic presentation, occurring in 93 of the 113 patients $(82 \%)$. In $7 \%$ of the patients, histologic examination of the embolus gave clues to the presence of a myxoma. ${ }^{7}$

While there are no established guidelines and there is debate regarding the treatment of acute stroke secondary to cardiac myxoma embolization, there have been around 20 case reports of thrombolysis with tPA use and even fewer reports of thrombectomy use in the treatment of acute stroke secondary to cardiac myxoma embolization. There have been mixed results with the use of tPA, with most patients having improvement, some having no change in symptoms, and some with development of intracranial hemorrhage. ${ }^{8-10}$ The effectiveness of tPA is likely decreased in those whose embolus is composed mainly of tumor rather than thrombotic material. ${ }^{9,10}$ The cases of mechanical thrombectomy have also shown varied results, ranging from TICI scores of $0-3$ with most patients having successful recanalization with TICI scores of $2 b$ and 3. ${ }^{6,10}$ Stent-retriever devices, aspiration thrombectomy devices, or both have been used and selection of device should take into account embolus location and consistency as well as the preference and experience of the neurointerventionalist. ${ }^{10}$

The diagnosis of cardiac myxoma is made using echocardiography. ${ }^{3,4}$ Treatment is surgical removal of the myxoma with diagnosis able to be confirmed by histologic examination of the tumor. Surgery should be performed as soon as it is safe to do so given cardiac myxomas' potential to embolize, metastasize, and cause formation of oncotic aneurysms, which can lead to disability or death. Prognosis is good with surgical removal with operative mortality rate being 0\%-3\%. Surgical complications include arrhythmias, which sometimes require pacing. ${ }^{1-4}$ There are no data establishing the safest time interval from stroke onset to treatment with anticoagulation or surgical excision. Risk of tumor recurrence following surgical excision is $2 \%-5 \%{ }^{7}$
It is difficult to establish guidelines for the treatment of acute stroke secondary to cardiac myxoma embolization given its rare occurrence and the etiology is usually not known prior to stroke presentation. ${ }^{9}$ However, the presented case and those reported in the literature suggest that thrombolytic and endovascular treatment of acute ischemic stroke secondary to cardiac myxoma can be safe and effective.

\section{Acknowledgment}

The authors thank Virtual Microscopy Core Lab, Department of Pathology, Wake Forest Baptist Medical Center for providing microscopic pathologic images.

\section{Study funding}

No targeted funding reported.

\section{Disclosure}

The authors report no disclosures relevant to the manuscript. Go to Neurology.org/N for full disclosures.

\begin{tabular}{|c|c|c|c|}
\hline Name & Location & Role & Contribution \\
\hline $\begin{array}{l}\text { Tamara } \\
\text { Barghouthi, } \\
\text { MD }\end{array}$ & $\begin{array}{l}\text { Wake Forest } \\
\text { Baptist Medical } \\
\text { Center, Winston- } \\
\text { Salem, NC }\end{array}$ & Author & $\begin{array}{l}\text { Drafting and revising of } \\
\text { the manuscript, } \\
\text { preparation of figure }\end{array}$ \\
\hline $\begin{array}{l}\text { Ava } \\
\text { Giugliano, } \\
\text { Do }\end{array}$ & $\begin{array}{l}\text { Wake Forest } \\
\text { Baptist Medical } \\
\text { Center, Winston- } \\
\text { Salem, NC }\end{array}$ & Author & $\begin{array}{l}\text { Drafting of the } \\
\text { manuscript }\end{array}$ \\
\hline $\begin{array}{l}\text { J.W. Lisa } \\
\text { Kim- } \\
\text { Shapiro, MD }\end{array}$ & $\begin{array}{l}\text { Wake Forest } \\
\text { Baptist Medical } \\
\text { Center, Winston- } \\
\text { Salem, NC }\end{array}$ & Author & $\begin{array}{l}\text { Preparation of } \\
\text { microscopic pathologic } \\
\text { images and pathologic } \\
\text { interpretation }\end{array}$ \\
\hline $\begin{array}{l}\text { Quang Vu, } \\
\text { MD }\end{array}$ & $\begin{array}{l}\text { Wake Forest } \\
\text { Baptist Medical } \\
\text { Center, Winston- } \\
\text { Salem, NC }\end{array}$ & Author & $\begin{array}{l}\text { Revising of the } \\
\text { manuscript, preparation } \\
\text { and editing of figure }\end{array}$ \\
\hline
\end{tabular}

\section{References}

1. Reynen K. Cardiac myxomas. N Engl J Med 1995;333:1610-1617.

2. Wen XY, Chen YM, Yu LL, et al. Neurological manifestations of atrial myxoma: a retrospective analysis. Oncol Lett 2018;16:4635-4639.

3. Salimi J, Najari K, Farshidmehr P, Toosi R, Naghavi B, Ramim T. Central nervous system and limb embolism concurrence due to atrial myxoma: a case report. J Tehran Heart Cent 2017;12:145-148.

4. Pinede L, Duhaut P, Loire R. Clinical presentation of left atrial cardiac myxoma: a series of 112 consecutive cases. Medicine 2001;80:159-172.

5. Yuan SM, Humuruola G. Stroke of a cardiac myxoma origin. Rev Bras Cir Cardiovasc 2015;30:225-234.

6. Uneda A, Suzuki K, Hirashita K, Yoshino K. Tandem cervical/intracranial internal carotid artery occlusion due to cardiac myxoma treated successfully with mechanical endovascular thrombectomy. Acta Neurochir 2016;158:1393-1395.

7. Ekinci EI, Donnan GA. Neurological manifestations of cardiac myxoma: a review of the literature and report of cases. Intern Med J 2004;34:243-249.

8. Kulkarni GB, Yadav R, Mustare V, Modi S. Intravenous thrombolysis in a patient with left atrial myxoma with acute ischemic stroke. Ann Indian Acad Neurol 2014;17: $455-458$.

9. Díaz Díaz A, García AM, Sedeño GP, García Rodríguez JR. Intravenous fibrinolysis for acute ischaemic stroke associated with left atrial myxoma: a case report. Neurologia 2018;33:267-268.

10. Chung YS, Lee WJ, Hong J, Byun JS, Kim JK, Chae SA. Mechanical thrombectomy in cardiac myxoma stroke: a case report and review of the literature. Acta Neurochir 2016;158:1083-1088. 


\section{Neurology}

\section{Pearls \& Oy-sters: IV and mechanical thrombolysis for ischemic stroke secondary to cardiac myxoma}

Tamara Barghouthi, Ava Giugliano, J.W. Lisa Kim-Shapiro, et al. Neurology 2019;93;975-977

DOI 10.1212/WNL.0000000000008549

\section{This information is current as of November 25, 2019}

\section{Updated Information \&} Services

References

Subspecialty Collections

Permissions \& Licensing

Reprints including high resolution figures, can be found at: http://n.neurology.org/content/93/22/975.full

This article cites 10 articles, 0 of which you can access for free at: http://n.neurology.org/content/93/22/975.full\#ref-list-1

This article, along with others on similar topics, appears in the following collection(s):

All Cerebrovascular disease/Stroke

http://n.neurology.org/cgi/collection/all_cerebrovascular_disease_strok

Cardiac

http://n.neurology.org/cgi/collection/cardiac

Embolism

http://n.neurology.org/cgi/collection/embolism

Other cerebrovascular disease/ Stroke

http://n.neurology.org/cgi/collection/other_cerebrovascular_disease_st roke

Information about reproducing this article in parts (figures,tables) or in its entirety can be found online at:

http://www.neurology.org/about/about_the_journal\#permissions

Information about ordering reprints can be found online:

http://n.neurology.org/subscribers/advertise

Neurology ${ }^{\circledR}$ is the official journal of the American Academy of Neurology. Published continuously since 1951, it is now a weekly with 48 issues per year. Copyright (O 2019 American Academy of Neurology. All rights reserved. Print ISSN: 0028-3878. Online ISSN: 1526-632X.

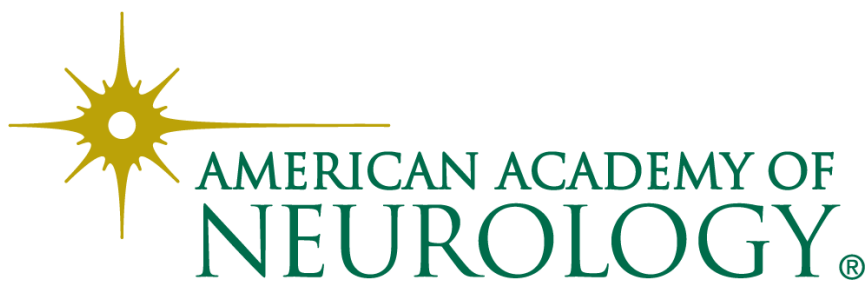

